\title{
A RARE CASE OF CARCINOMATOUS ENCEPHALITIS AS THE PRESENTING FEATURE OF OCCULT LUNG ADENOCARCINOMA- A DIAGNOSTIC DILEMMA
}

Sapre Chinmaye1, Deshpande Shubhangi², Adalja Devina ${ }^{3}$

${ }_{1}^{1}$ Assistant Professor, Department of Medicine, GMERS, Gotri, Vadodara, Gujarat, India.

${ }^{2}$ Associate Professor, Department of Medicine, GMERS, Gotri, Vadodara, Gujarat, India.

3Intern, GMERS, Gotri, Vadodara, Gujarat, India.

HOW TO CITE THIS ARTICLE: Chinmaye S, Shubhangi D, Devina A. A rare case of carcinomatous encephalitis as the presenting feature of occult lung adenocarcinoma- a diagnostic dilemma. J. Evolution Med. Dent. Sci. 2018;7(25):2967-2968, DOI: $10.14260 /$ jemds/2018/668

\section{PRESENTATION OF CASE}

A 45-year-old female with past history of ischaemic stroke 4 months back presented with complaints of one episode of generalised tonic-clonic seizure followed by altered sensorium for the last 10 days. There was no history of fever, cough with expectoration, weight loss, anorexia, headache, visual disturbances or bowel and bladder involvement. There was no past history of pulmonary tuberculosis, epilepsy, diabetes and hypertension. There was no history of any addictions. On examination, the patient was haemodynamically stable. Patient was conscious, but not responding to verbal commands. Systemic examination showed hyperreflexia on right side with extensor plantars. Laboratory investigations showed a normal haemogram with ESR of $52 \mathrm{~mm} /$ hour, normal renal function test and liver function test. Chest x-ray (Figure 1) showed a homogenous opacity in the left upper lobe. An MRI Brain with gadolinium contrast (Figure 2 and 3) was done, which showed multiple tiny nodular ring enhancing lesions scattered throughout both cerebral and cerebellar hemispheres. These lesions appeared hyperintense on T2W and FLAIR. No foci of blooming were seen on GRE (T2*) images. No evidence of leptomeningeal enhancement was seen. Based on the images, differential diagnoses were tuberculosis $\mathrm{v} / \mathrm{s}$ disseminated neurocysticercosis $\mathrm{v} / \mathrm{s}$ malignancy considering the lesion on the lung. A CSF analysis showed normal counts, protein and normal ADA. Considering the lesion present on the chest $\mathrm{x}$ ray CECT Thorax (Figure 4) was done, which showed multiple cavitatory nodular lesions on the left upper lobe and lower lobes which appeared to be of infective aetiology. The patient's HIV status was negative and as there was a possibility of malignancy a CT-guided lung biopsy was done which showed a lung adenocarcinoma which was positive for PAN-CK and CK-7 on immunohistochemistry. Due to the limited resources, we had to refer the patient to a higher centre for further management.

\section{DIFFERENTIAL DIAGNOSES}

- Tuberculoma.

- Neurocysticercosis.

- Carcinomatous encephalitis.

'Financial or Other Competing Interest': None.

Submission 06-05-2018, Peer Review 02-06-2018,

Acceptance 08-06-2018, Published 18-06-2018.

Corresponding Author:

Dr. Sapre Chinmaye,

\#139/140 Orchid Bunglows,

Old Padra Road, Near AIIMS Oxygen,

Vadodara-390020, Gujarat, India.

E-mail: chinmayesapre16@gmail.com

DOI: $10.14260 /$ jemds $/ 2018 / 668$

(c) $(7)$

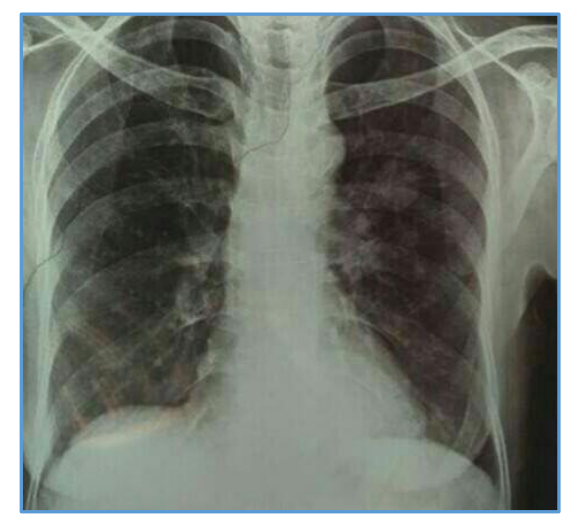

Figure 1. Chest X-Ray showing well-defined opacity in the Left Middle Zone

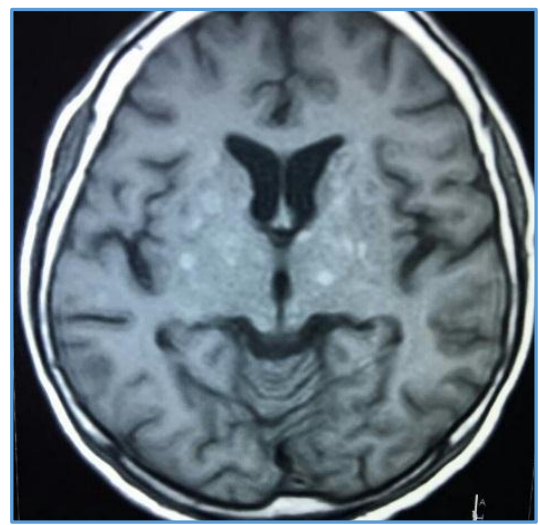

Figure 2. CT Head T1 Sequence showing multiple small lesions involving the Parietal and Temporal Lobe without any Mass Effect or Oedema

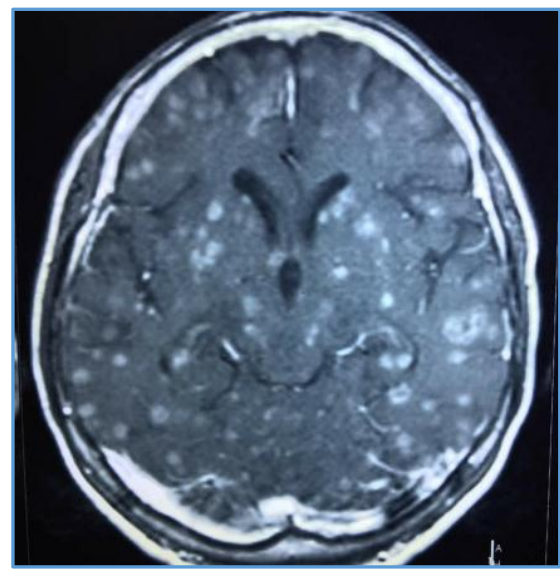

Figure 3. CT Head T2 Sequence showing the post contrast enhancement of multiple well-defined Circumscribed Lesions 


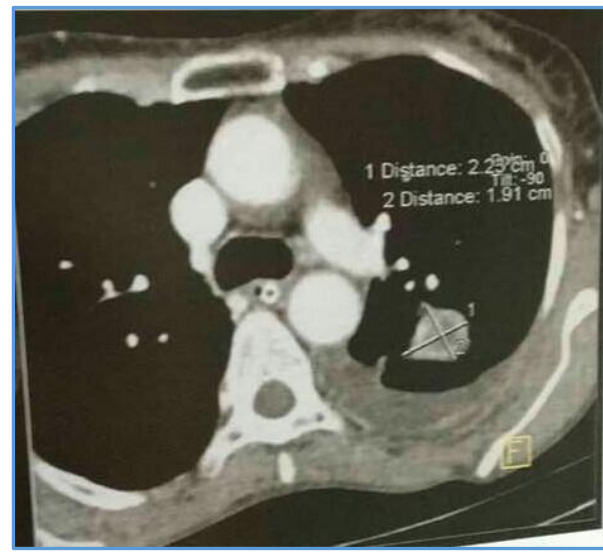

Figure 4. HRCT Thorax showing Lesion in the Middle Zone of the Left Lung

\section{PATHOLOGICAL DISCUSSION}

Brain metastasis is the most common intracranial neoplasm of the brain and the most common malignancy metastasising to the brain is CA lung. The small cell variant was found to be the most common variant of lung cancer.[1] Most of the times, metastases are characterised by the presence of nodules or single masses.[2] Carcinomatous encephalitis is an uncommon form of this metastasis where there are multiple lesions, but in the absence of any mass effect or perilesional oedema. ${ }^{[3,4]}$ Considering the presence of multiple lesions, the presentation of this condition can be varied. These varied presentations of the condition prompt us to think of toxic, metabolic or infectious causes first. The peculiarity of carcinomatous encephalitis is also that CSF reports are nonspecific, as there may be no meningeal involvement and CT scans also do not detect the presence of these small nodules.[5] Thus, making gadolinium enhanced MRI as the investigation of choice. The lesions on the MRI can be calcified, haemorrhagic or even normal.[6] In the absence of a known malignancy, multiple ring enhancing nodules present in the cortical and subcortical regions are more common with neurocysticercosis and tuberculosis. ${ }^{[7]}$ Our patient as previously described had no symptoms of any malignancy and the presence of a lesion in the lung prompted us to think of tuberculosis and disseminated neurocysticercosis as the principal possibilities. Being a country where the prevalence of tuberculosis is high, ${ }^{[8]}$ it prompts a diagnostician to think of it as the first diagnosis. Some of the pitfalls of working in a limited resource setup is that many a times due to lack of resources common conditions are assumed to be the diagnosis and treatment is carried out empirically leading to delay in the actual diagnosis. This delay in diagnosis leads to a worse prognosis and also leads to relatives taking discharge against medical advice. In this case we immediately went ahead with a CT-guided lung biopsy prior to starting any treatment, which showed the presence of adenocarcinoma of lung as the primary condition. Despite the importance of this clinical condition, our literature search yielded only one case with a similar presentation.[6] The conclusion derived from this case is that the presentation of carcinomatous encephalitis is non-specific, which poses a diagnostic challenge. Even in resource limited set-ups it should be considered in the differential diagnosis of an MRI showing multiple nodular ring enhancing lesions and empiric therapy to cover the most common organism, that is tuberculosis without thorough work-up should be avoided.

\section{FINAL DIAGNOSIS}

Carcinomatous encephalitis secondary to adenocarcinoma of the lung.

\section{REFERENCES}

[1] Tabouret E, Chinot O, Metellus P, et al. Recent trends in epidemiology of brain metastases: an overview. Anticancer Res 2012;32(11):4655-62.

[2] Posner JB, Davis FA. Neurological complications of cancer. Annals of Neurology 1996;39(2):279.

[3] Olsen WL, Winkler ML, Ross DA. Carcinomatous encephalitis: CT and MR findings. Am J Neuroradiol 1987;8:553-4.

[4] Madow L, Alpers BJ. Encephalitic form of metastatic carcinoma. Arch Neurol Psychiatry 1951;65(2):16173.

[5] Nemzek W, Poirier V, Salamat MS, et al. Carcinomatous encephalitis (miliary metastases): lack of contrast enhancement. AJNR 1993;14(3):5402.

[6] Ribeiro HB, Paiva TF Jr, Mamprin GP, et al. Carcinomatous encephalitis as clinical presentation of occult lung adenocarcinoma: case report. Arq Neuropsiquiatr 2007;65(3B):841-4.

[7] Shetty G, Avabratha KS, Rai BS. Ring-enhancing lesions in the brain: a diagnostic dilemma. Iran J Child Neurol 2014;8(3):61-4.

[8] TB Statistics for India. National and state statistics. TB Facts.org. Jun 14 Cited 2017. http://www.tbfacts.org/tb-statistics-india/ 